\title{
A new inducible expression system in a transformed green alga, Chlorella vulgaris
}

\author{
Y.F. Niu*, M.H. Zhang*, W.H. Xie, J.N. Li, Y.F. Gao, W.D. Yang, J.S. Liu \\ and H.Y. Li
}

Key Laboratory of Aquatic Eutrophication and Control of Harmful Algal Blooms, Guangdong Higher Education Institute, Jinan University, Guangzhou, China

*These authors contributed equally to this study.

Corresponding author: H.Y. Li

E-mail: thyli@jnu.edu.cn

Genet. Mol. Res. 10 (4): 3427-3434 (2011)

Received April 18, 2011

Accepted September 8, 2011

Published October 21, 2011

DOI http://dx.doi.org/10.4238/2011.October.21.1

\begin{abstract}
Genetic transformation is useful for basic research and applied biotechnology. However, genetic transformation of microalgae is usually quite difficult due to the technical limitations of existing methods. We cloned the promoter and terminator of the nitrate reductase gene from the microalga Phaeodactylum tricornutum and used them for optimization of a transformation system of the microalga Chlorella vulgaris. This species has been used for food production and is a promising candidate as a bioreactor for large-scale production of value-added proteins. A construct was made containing the $C A T$ (chloramphenicol acetyltransferase) reporter gene driven by the nitrate reductase promoter. This construct was transferred into the C. vulgaris genome by electroporation. Expression of $C A T$ in transgenic Chlorella conferred resistance to the antibiotic chloramphenicol and enabled growth in selective media. Overall efficiency for the transformation was estimated to be approximately $0.03 \%$, which is relatively high compared with other available Chlorella transformation systems. Expression of CAT was induced in the presence of nitrate and inhibited in the presence of ammonium as
\end{abstract}


a sole nitrogen source. This study presented an inducible recombinant gene expression system, also providing more gene regulation elements with potential for biotechnological applications.

Key words: Nitrate reductase; Inducible promoter; Gene transfer; Electroporation; Microalga

\section{INTRODUCTION}

Microalgae provide most of the organic matter serving as food for aquatic life. Chlorella vulgaris is an essential phytoplankton used as live feed for fisheries with a high content of proteins and fatty acids. In addition, due to its fast growth and low cost, C. vulgaris is thus a promising candidate bioreactor for the large-scale production of value-added proteins. To make a Chlorella microalgal bioreactor, an appropriate genetic transformation system is needed to ensure the expression of the target gene in transgenic Chlorella.

The critical step for genetic transformation is to generate a plasmid vector containing all the genetic elements for expression. The vector involves the manipulation of selection marker (usually an antibiotic resistance gene) expression cassettes for either selection of plasmid in the bacteria or selection of gene transfer in the host organism, and another target gene expression cassette for expression in the host organism. However, production of the selection marker protein is not wanted after obtaining the transgenic organism. Constitutive production of heterologous proteins in transgenic cells is sometimes problematic, since some proteins might affect the growth of transgenic cells or cells may dislike it, etc. One of the feasible choices is to employ an inducible promoter to confine the expression of the selection marker protein to the transgenic organism. Development of inducible promoters is also essential for the design of transformation vectors allowing expression of the selection marker as well as the gene of interest in the target organisms.

Some heterologous promoters widely used in plant transformation have been used in the genetic transformation of microalgae. For example, cauliflower mosaic virus (CaMV) 35S promoter and p1'2' Agrobacterium promoter were tested to drive the expression of report gene GUS in dinoflagellates Amphidinium and Symbiodinium (Leon and Fernandez, 2007). However, due to the unique nuclear characteristics of these microalgae, the expression of foreign genes under the control of heterologous promoters was affected, unexpectedly, as in higher plants, exhibiting relatively low expression levels and usual transient expression. In contrast, the RBCS2 promoter from the unicellular green alga Chlamydomonas reinhardtii showed higher efficiency than the $35 \mathrm{~S}$ promoter in transgenic Dunaliella salina (Sun et al., 2005). In the pennate diatom Cylindrotheca fusiformis and centric diatom Thalassiosira pseudonana, relatively high transformation efficiencies were achieved using their own fucoxanthin chlorophyll a/c binding protein (fcp) promoter or nitrate reductase (NR) promoter (Poulsen and Kröger, 2005; Poulsen et al., 2006). High efficiency transformation of the diatom Phaeodactylum tricornutum was achieved with a promoter from the diatom C. fusiformis (Miyagawa et al., 2009). In the case of Chlorella, development of genetic transformation has been slow. A plant ubiquitin gene promoter was used to drive the expression of a gene encoding mature rabbit neutrophil peptide-1 (NP-1) in Chlorella ellipsoidea cells. In another study, C. ellipsoidea was transformed with a vector containing the flounder growth hormone gene (fGH) under the control of the $35 \mathrm{~S}$ promoter, and the phleomycin resistance Sh ble gene under the control of 
the Chlamydomonas RBCS2 gene promoter. Over $400 \mu \mathrm{g}$ fGH protein expression per one liter of culture containing $1 \times 10^{8}$ cells $/ \mathrm{mL}$ was estimated by ELISA (Kim et al., 2002). However, the expression levels of these foreign genes in transformed Chlorella were still relatively low. Therefore, new and effective endogenous promoters are urgently needed to be isolated for efficient expression of foreign genes in Chlorella. In this study, we identified the promoter of the $N R$ gene from P. tricornutum, which can drive inducible expression of the CAT report gene in transformed $C$. vulgaris in the presence of nitrate as the sole nitrogen source.

\section{MATERIAL AND METHODS}

\section{Microalgae materials, culture conditions and nitrate induction treatment}

C. vulgaris was preserved in the Algal Collection Center of Jinan University in Guangzhou, China. Chlorella was grown in BG11 medium in Erlenmeyer flasks, which was filter-sterilized through $0.22 \mu \mathrm{m}$ filters (Millipore, USA). Cultures in liquid medium or on the plate were grown at $25^{\circ} \pm 1^{\circ} \mathrm{C}$ in an artificial climate incubator. Cool-white fluorescent tubes provided an irradiance of $200 \mu \mathrm{mol}$ photons $\mathrm{m}^{-2} \mathrm{~s}^{-1}$ under long-daylight conditions (15/9 h light/dark regime).

\section{Cloning of NR promoter and terminator and construction of CAT expression cassette}

Nitrate reductases of $P$. tricornutum (GeneBank accession: EEC44781) were revealed by BLAST search in NCBI website. The predicted promoter and terminator regions of the $N R$ gene were cloned by PCR using genomic DNA of $P$. tricornutum as a template with primers designed according to the genome sequence. Primer pairs for the NR promoter were 5'-TTGAGATGGTGGTTCCACTGTGCAG-3' and 5'-CGTTCGCACAAGTGGTGACTTTGAA-3'; and primer pairs for the NR terminator were 5'-AAGTTCTTGACTGATTGTCATATC-3'; and 5'-CTAACGCAGCTTAGACATAAACC-3'.

The reporter CAT coding region was cloned by PCR from plasmid pLysS using CAT primers: 5'- ATGGAGAAAAAAATCAC-3', 5'- TTACGCCCCGCCCTGC-3'. To construct the CAT expression cassette containing NR promoter and terminator, overlap extension PCR was performed. DNA fragments were mixed in a $10 \mu \mathrm{L}$ total volume of reaction mixture containing Phusion DNA polymerase (New England BioLabs, Ipswich, USA). Each PCR reaction was programmed by denaturation $\left(98^{\circ} \mathrm{C}\right.$ for $\left.30 \mathrm{~s}\right)$, annealing $\left(55^{\circ} \mathrm{C}\right.$ for $\left.30 \mathrm{~s}\right)$, and extension $\left(72^{\circ} \mathrm{C}\right.$ for $0.5 \mathrm{~min}$ per $\mathrm{kb}$ according to the length of the longest piece) for 25-30 cycles, then a final extension at $72^{\circ} \mathrm{C}$ for $10 \mathrm{~min}$. To the fused CAT expression cassette was then added dATP at its 3'-end with Taq DNA polymerase and cloned into a pMD18-T vector (TaKaRa, Dalian, China). After confirmation by DNA sequence analysis, the resultant plasmid was named pPt-ApCAT (Figure 1). CAT expression was therefore under the control of the NR promoter/terminator.

\section{Generation of transgenic $C$. vulgaris by electroporation}

The plasmid pPt-ApCAT described above was used to transform C. vulgaris by electroporation using a Bio-Rad GenePulser Xcell apparatus (Bio-Rad, USA). Chlorella cells in the exponential phase were collected by centrifuge at $1350 \times \mathrm{g}$ for $10 \mathrm{~min}$. A pellet containing the equivalent of $3 \times 10^{6}$ Chlorella cells was resuspended with $150 \mu \mathrm{L} 1.0 \mathrm{~mol} / \mathrm{L} \mathrm{NaCl}$, 
then mixed with $150 \mu \mathrm{L} 0.1 \mathrm{~mol} / \mathrm{L}$ mannitol, and kept on ice for $30 \mathrm{~min}$. Suspension aliquots of $0.4 \mathrm{~mL}$ in volume were mixed with $0.4 \mu \mathrm{g}$ plasmid pPt-ApCAT then transferred into an electroporation cuvette (Gene Pulser/MicroPulser Cuvette, $0.4 \mathrm{~cm}$ gap, Bio-Rad). After electroporation, cells were transferred into $10 \mathrm{~mL} \mathrm{BG11} \mathrm{medium,} \mathrm{kept} \mathrm{dark} \mathrm{for} 2 \mathrm{~h}$, then normally incubated for $24 \mathrm{~h}$ (12L:12D). Afterwards, cells were collected by centrifugation at $1500 \times \mathrm{g}$ for $5 \mathrm{~min}$ and resuspended in $1 \mathrm{~mL}$ medium. To plate cells on Petri dishes, cells were finally spread on BG11 selection medium supplemented with $5 \mathrm{~g} / \mathrm{L}$ agar containing various concentrations of chloramphenicol (200, 250, $300 \mathrm{mg} / \mathrm{L})$.

\section{Analysis of transgenic Chlorella}

After 3 weeks of incubation of the plates under standard growth conditions for $C$. vulgaris, putative transformed colonies emerging on the selection medium were counted. Surviving colonies were picked and inoculated into liquid BG11 medium containing $200 \mathrm{mg} / \mathrm{L}$ chloramphenicol, then transferred for five more successive cycles on selection medium to obtain stable transgenic Chlorella. To indicate the integration of the CAT gene in transgenic Chlorella, genomic DNA was extracted and PCR analysis was performed with CAT primers cat1: 5'- ATGGAGAAAAAAATCACTG-3', and cat2: 5'- TAAGCATTCTGCCGACAT-3'. PCR product was further confirmed by sequencing analysis. Confirmed cultures were then subjected to inducer treatment, by inoculation in liquid BG11 medium containing different sole nitrogen sources of either nitrate $\left(\mathrm{NaNO}_{3}\right)$ or ammonium $\left(\mathrm{NH}_{4} \mathrm{Cl}\right)$ supplemented with chloramphenicol.

\section{RESULTS}

\section{Construction of CAT expressing vector under the control of NR promoter/terminator}

The predicted 565-bp NR promoter and 352-bp NR terminator regions were amplified by PCR, and confirmed by sequencing analysis. The CAT coding region was inserted in between the NR promoter and terminator by overlap extension PCR. The functional CAT expression cassette was inserted in TA cloning vector pMD18-T. The resultant plasmid pPt-ApCAT was $4.4 \mathrm{~kb}$ in length, confirmed by restriction analysis and sequencing analysis, demonstrating the successful construction of the vector. A schematic map of transformation vector pPt-ApCAT is shown in Figure 1.

\section{Selection and chloramphenicol resistance of transgenic Chlorella}

Chlorella cells were transformed by electroporation with plasmid pPt-ApCAT. Pulsed Chlorella cells were allowed to recover in non-selective suspension culture for $24 \mathrm{~h}$, which was shown though testing to be important for high transformation efficiency. Then transformed cells were spread on chloramphenicol containing agar plates. After 3 weeks, surviving Chlorella colonies were picked and transferred into liquid medium for successive culture. Figure 2 shows transformed Chlorella cells determined by chloramphenicol resistance. Transformed cells with plasmid pPt-ApCAT expressing CAT grew well on the selection plates supplemented with $200 \mathrm{mg} / \mathrm{L}$ chloramphenicol (Figure 2). These results demonstrated that CAT was successfully expressed in the transformed Chlorella and functioned properly to exhibit chloramphenicol resistance. An overall efficiency for our transformation was estimated to be 
approximately one transgenic colony per 3000 Chlorella cells, relatively high compared with any C. vulgaris nuclear transformation system ever reported (Apt et al., 1996; Chen et al., 2001; Kim et al., 2002).
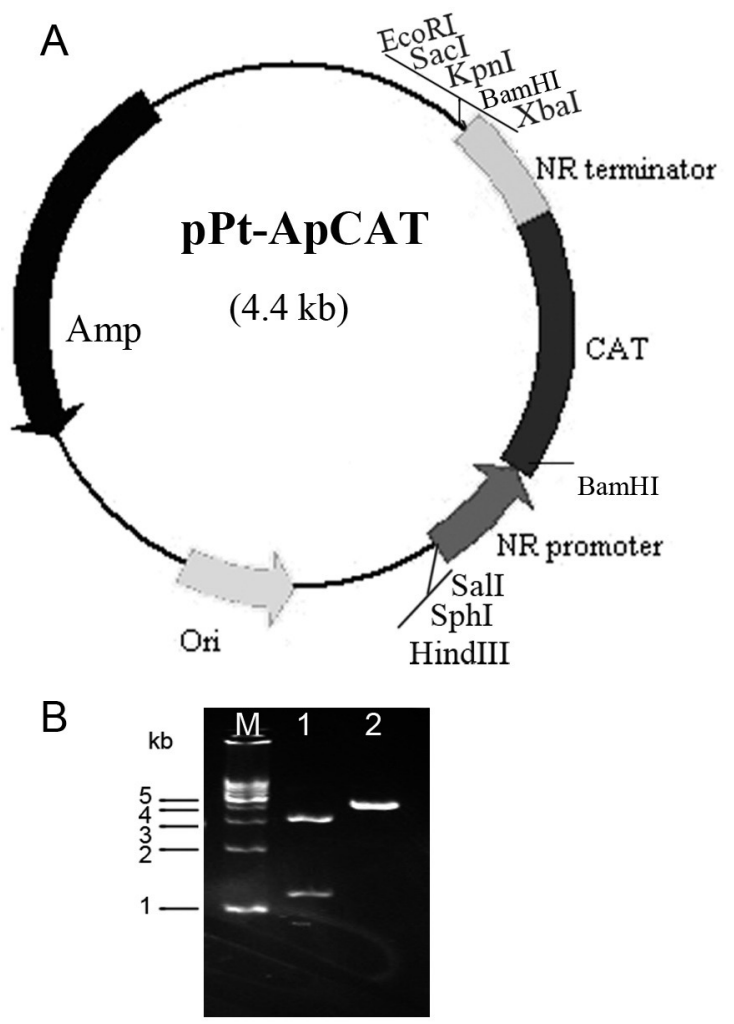

Figure 1. Diagram showing construct pPt-ApCAT. A. Plasmid map of pPt-ApCAT, annotations on the map are as follows: $\mathrm{CAT}=$ report gene encoding chloramphenicol acetyltransferase; Amp $=$ ampicillin resistance gene cassette. B. Restriction analysis of pPt-ApCAT. Lane $M=1 \mathrm{~kb}$ marker, lane $1=\mathrm{pPt}$-ApCAT digested with BamHI, an expected $1.15-\mathrm{kb}$ band was obtained, indicating the correct insertion of CAT cassette and its orientation.

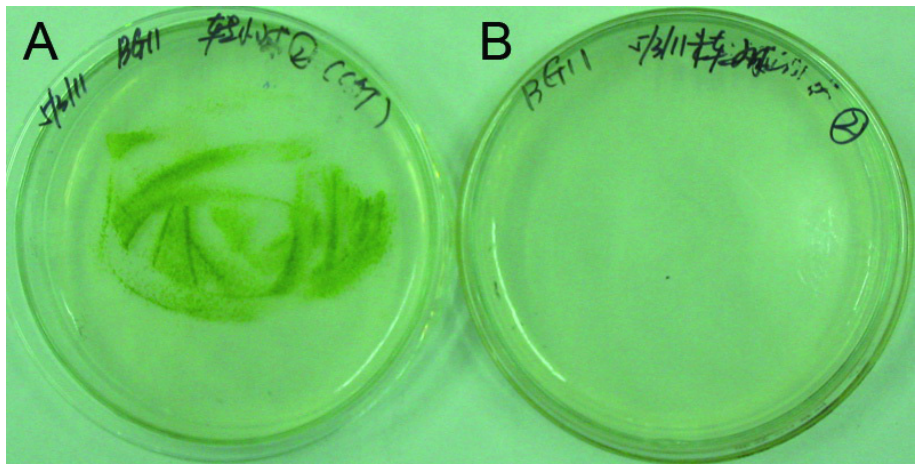

Figure 2. Transgenic Chlorella streaked on plates in the presence of nitrate supplemented with chloramphenicol. 
Transgenic cells expressing CAT were determined on plates in the presence of nitrate supplemented with $200 \mathrm{mg} / \mathrm{L}$ chloramphenicol (A), while untransformed wild type cells could not grow (B).

\section{Analysis of transgenic Chlorella}

Transformed Chlorella cells successively subcultured in liquid medium were then subjected to PCR analysis using CAT primers, and the size of the PCR-amplified CAT cassette was calculated to be $0.6 \mathrm{~kb}$. Gel electrophoresis showed that a specific $0.6-\mathrm{kb}$ band was present in transformed Chlorella cells (Figure 3, lane 1) while absent in wild-type cells (Figure 3 , lane 2), indicating that the $C A T$ cassette was successfully incorporated into the microalgal nuclear genome.

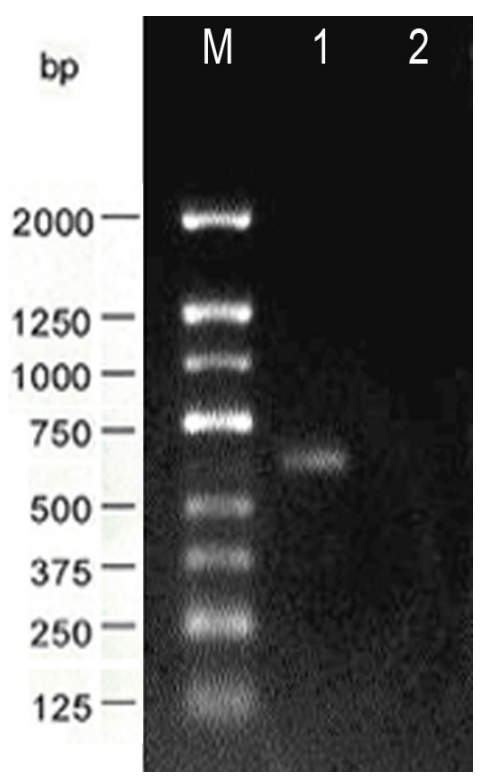

Figure 3. PCR analysis of transgenic Chlorella. Lane $M=125$ bp DNA ladder; lane $1=$ PCR of transgenic Chlorella; lane 2 = negative control of wild type Chlorella; a $0.6-\mathrm{kb}$ band in lane 1 indicates the expected CAT PCR product.

\section{Inducible expression analysis of transgenic Chlorella}

Transgenic Chlorella cells were inoculated in the liquid medium composed of different nitrogen sources of either nitrate $\left(\mathrm{NaNO}_{3}\right)$ or ammonium $\left(\mathrm{NH}_{4} \mathrm{Cl}\right)$. After 3 weeks, transgenic Chlorella in the medium containing ammonium did not grow at all; in contrast, those in the medium containing nitrate grew normally (Figure 4). These results implicate that CAT expression with the NR promoter was switched off in the presence of ammonium and induced by nitrate in transgenic Chlorella. This regulatory system with the $P$. tricornutum NR promoter was useful for C. vulgaris as well.

Transgenic cells were examined for CAT expression in liquid medium in the presence of either nitrate or ammonium as sole nitrogen source supplemented with $200 \mathrm{mg} / \mathrm{L}$ chloram- 
phenicol. Cells grew normally in the presence of $\mathrm{NaNO}_{3}$ (left), while cells inoculated in the presence of $\mathrm{NH}_{4} \mathrm{Cl}$ did not survive from Cam, with no growth even after 3 weeks (right).

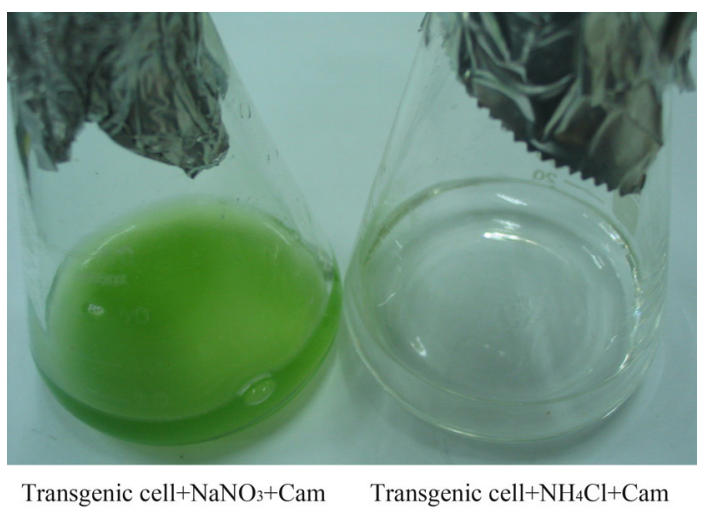

Figure 4. Inducible expression of CAT reporter in transgenic Chlorella.

\section{DISCUSSION}

Development of microalgae biotechnology based on genetic engineering has been slow compared with higher plants. Although foreign gene expression in a few microalgae species has been achieved, the relatively lower expression level makes the development of an effective industrial-scale microalgae bioreactor imperative. One of the major requirements to develop a highly efficient microalgae expression system is to obtain a suitable promoter. This study reported the application of a P. tricornutum NR promoter and development of a specific genetic transformation system which can drive inducible expression of introduced genes in the microalga Chlorella. Moreover, the high transformation efficiency makes the approach a powerful tool for the eventual development of a microalgae bioreactor.

Constitutive production of heterologous proteins in transgenic cells is sometimes problematic, since some proteins might affect the growth of transgenic cells or cells may not like it or other possible effects. Using an inducible expression system with the endogenous promoter could be an efficient way to solve such problems. Expression of nitrate reductase has been shown to be induced in the presence of nitrate in higher plants. Nitrate reductase is the main enzyme in plants capable of fixing nitrogen. And it has been demonstrated that the NR promoter is inducible so that it can be used for controllable expression of foreign genes (Poulsen and Kröger, 2005, Miyagawa et al., 2009). Since nitrate can be used as component of culture medium, a nitrate inducible promoter could be an ideal candidate for the high efficiency expression of target genes. Development of inducible promoters in microalgae is also an essential step for the design of transformation vectors allowing expression of the selection marker as well as the gene of interest in target microalgae. Microalgae are currently considered ideal bioreactors because of their rapid growth rates and high yield of protein and lipid. Furthermore, unlike other production systems, microalgae can be easily cultured in outdoor ponds or well-established indoor bioreactors or fermentors (Pruvost et al., 2009). Since C. vulgaris is a widely used live food for fisheries, available for direct utilization and/or downstream processing, our transfor- 
mation system should provide an efficient tool for genetic engineering of $C$. vulgaris for the commercial production of value-added genes or improvement of the feeding value.

This study indicates the ammonium repression for expression of a CAT reporter, in accordance with previous observations that ammonium deficiency is required for full expression of the Nial gene encoding nitrate reductase in C. reinhardtii (Loppes et al., 1999). However, structure and functional properties of the NR promoter of $P$. tricornutum has not been characterized yet. Identification of nitrogen-response elements has been complicated by the lack of sequence homology among species in the promoter of the $N R$ gene. Further studies are needed to determine the factors regulating $N R$ transcription in microalgae.

\section{ACKNOWLEDGMENTS}

Research was supported by the National Science and Technology Support Program (\#2011BAD14B03), Science and Technology Project of Guangdong (\#2010B030600005, \#2009B020301002, \#2009B050600005), and the Fundamental Research Funds for the Central Universities.

\section{REFERENCES}

Apt KE, Kroth-Pancic PG and Grossman AR (1996). Stable nuclear transformation of the diatom Phaeodactylum tricornutum. Mol. Gen. Genet. 252: 572-579.

Chen Y, Wang Y, Sun Y, Zhang L, et al. (2001). Highly efficient expression of rabbit neutrophil peptide-1 gene in Chlorella ellipsoidea cells. Curr. Genet. 39: 365-370.

del Campo JA, Garcia-Gonzalez M and Guerrero MG (2007). Outdoor cultivation of microalgae for carotenoid production: current state and perspectives. Appl. Microbiol. Biotechnol. 74: 1163-1174.

Kim DH, Kim YT, Cho JJ, Bae JH, et al. (2002). Stable integration and functional expression of flounder growth hormone gene in transformed microalga, Chlorella ellipsoidea. Mar. Biotechnol. 4: 63-73.

Leon R and Fernandez E (2007). Nuclear transformation of eukaryotic microalgae: historical overview, achievements and problems. Adv. Exp. Med. Biol. 616: 1-11.

Loppes R, Radoux M, Ohresser MC and Matagne RF (1999). Transcriptional regulation of the Nia1 gene encoding nitrate reductase in Chlamydomonas reinhardtii: effects of various environmental factors on the expression of a reporter gene under the control of the Nial promoter. Plant Mol. Biol. 41: 701-711.

Miyagawa A, Okami T, Kira N, Yamaguchi H, et al. (2009). High efficiency transformation of the diatom Phaeodactylum tricornutum with a promoter from the diatom Cylindrotheca fusiformis. Phycol. Res. 57: 142-146.

Poulsen N and Kröger N (2005). A new molecular tool for transgenic diatoms: control of mRNA and protein biosynthesis by an inducible promoter-terminator cassette. FEBS J. 272: 3413-3423.

Poulsen N, Chesley PM and Kröger N (2006). Molecular genetic manipulation of the diatom Thalassiosira pseudonana (Bacillariophyceae). J. Phycol. 42: 1059-1065.

Pruvost J, Van Vooren G, Cogne G and Legrand J (2009). Investigation of biomass and lipids production with Neochloris oleoabundans in photobioreactor. Bioresour. Technol. 100: 5988-5995.

Sun Y, Yang Z, Gao X, Li Q, et al. (2005). Expression of foreign genes in Dunaliella by electroporation. Mol. Biotechnol. 30: 185-192. 